\title{
Nutrient reabsorption mechanism adapted to low phosphorus in wild and cultivated soybean varieties
}

\author{
wenyue shen $^{1}$, Rui $\mathrm{Guo}^{2}$, yaxuan zhao ${ }^{1}$, danping liu ${ }^{1}$, jing chen $^{1}$, ningning miao ${ }^{1}$, shujuan \\ gao $^{1}$, tao zhang ${ }^{1}$, and lianxuan $\operatorname{shi}^{1}$ \\ ${ }^{1}$ Affiliation not available \\ ${ }^{2}$ Chinese Academy of Agricultural Sciences
}

December 2, 2020

\begin{abstract}
Phosphorus (P) is an essential nutrient element for plants. Wild soybean (Glycine soja) expresses higher tolerance to P-limited environment compared to cultivated soybeans (Glycine max). In this study, the response of ionomics and metabonomics in young and old leaves of two soybean varieties under low $\mathrm{P}$ were studied. Our results showed that the tolerance of low $\mathrm{P}$ in wild soybean can be improved by promoting the accumulation of $\mathrm{Mg} 2+, \mathrm{Fe} 3+$, and $\mathrm{SO} 42-$ in young and old leaves and the transportation of NO3- and H2PO4- from old to young leaves. The young and old leaves of wild soybean under low $\mathrm{P}$ accumulated sugars including maltose and sucrose, amino acids including asparagine and glutamine, and nitrogenous compounds including tyramine, and enhanced the tricarboxylic acid cycle metabolism, especially in young leaves, but decreased the content of hexose-phosphate metabolites. Our experiment indicated that wild soybean can tolerate low P by enhancing the energy metabolism in young and old leaves, promoting the transportation and reuse of sugars and amino acid metabolites from old to young leaves, and mobilizing Pi from hexose-phosphate of old leaves to young leaves. Our results provide a new insight for the cultivation of new soybean varieties with tolerance to $\mathrm{P}$ deficiency.
\end{abstract}

\section{Introduction}

Phosphorus (P) is one of the most important nutrient elements for plant growth and reproduction, which is closely related to the yield and quality of crops. Besides, $\mathrm{P}$ uptake and utilization are also important determinants for plant community composition in terrestrial ecosystems (Xu, He, Yan \& Song 2007). The soil total $\mathrm{P}$ content is generally high, but most $\mathrm{P}(20-80 \%)$ is in the form of organic $\mathrm{P}$ which cannot be easily used by plants, and therefore, the plant growth is easily inhibited by P deficiency (Krmer \& Green 2000). Approximately 30-40\% of agricultural land in worldwide suffers from low productivity because of $\mathrm{P}$ resource deficiency according to the statistics at a global scale, and which is also frequently observed in natural ecosystems (Dodds, Johnson \& Priscu1989; Runge-Metzger 1995). Cheap P resources in the world are estimated to be exhausted by 2050 (Vance, Uhde-Stone \& Allan 2010). In addition, the use of large amounts of phosphate fertilizer can lead to serious environmental pollution problems including water eutrophication (Brown, George, Barrett, Stephen \&Philip 2013). How to improve the efficiency of P absorption and utilization for plants is important to maintain the natural ecosystem stability and the crop yield in agricultural ecosystems.

$\mathrm{P}$ is highly mobile in plants. Under low $\mathrm{P}$ conditions, the recycling of $\mathrm{P}$ from old to young leaves is an effective way to improve the efficiency of $\mathrm{P}$ utilization, which can help plants tolerate the $\mathrm{P}$ deficiency (Kyla \& William 2015; Richardsonet al. 2011). The leaf $\mathrm{P}$ concentration and electron transfer rate under low $\mathrm{P}$ conditions might be affected by the leaf age in potato, and nutrients in senescent tissues transported to young tissues and reproductive organs, especially under stress (Balemi 2011; Zhou et al. 2020). The P reutilization 
rate can be up to $50 \%$ in soybean (Crafts-Brandner 1992). However, differences in physiological mechanisms of cultivated crops and wild plants regarding their adaptations to low $\mathrm{P}$ conditions, and the redistribution and utilization of nutrients between young and old leaves are still not clear.

Cultivated soybean, Glycine max, is one of the most important economic crops, which is frequently affected by $\mathrm{P}$ deficiency. Under low $\mathrm{P}$, leaf area and photosynthetic rate are significantly decreased, flower and pod abscission are increased, and the yield and quality are reduced (Fredeen, Raab \& Terry 1990). Wild soybean (Glycine soja) is the related species of cultivated soybean, which has a higher resistance to disease, insect, drought, and nutrient deficiency than cultivated soybean. Our previous results found that wild soybean can tolerate low nitrogen and drought stresses by maintaining nutrient balance and stable tricarboxylic acid (TCA) cycle and increasing the concentration of metabolites such as amino acids (Wanget al. 2019; Zhao et al. 2019). Nevertheless, the adaptation mechanism of wild soybean and cultivated soybean under low $\mathrm{P}$ conditions is still not very clear.

Metabolomics defined as a comprehensive analysis of all small molecular metabolites in biological systems has become one of the most important methods to study metabolic pathway changes and tolerance mechanisms under adversity stresses in plants (Hillenmeyer et al.2010). For instance, several studies investigated the adaptive mechanism of white lupin, maize, and barley to low $\mathrm{P}$ conditions, and the metabolic response of soybean and rice to salt stress (Fu et al. 2018; Ganieet al. 2015; Huang et al. 2008; Müller, Victoria, Karsten \& Christian 2015; Zhang, Yang, Li \& Shi 2016). Moreover, a conjoint analysis of metabolomics and ionomics has been widely used to examine molecular mechanisms how crops adapt to adversity stresses including deficiencies of $\mathrm{N}$ and $\mathrm{P}$ and drought and salt stress (Ding, Jia, Wang, Xiao \& Zhang 2017; Guoet al. 2016; Guo et al. 2018; Liu et al. 2019). However, the responses in metabolomics and ionomics of wild and cultivated soybeans and the transportation and reuse of nutrients in young and old leaves of wild soybean under low $\mathrm{P}$ conditions are still not well-understood, which is important to produce cultivated soybean with high tolerance to low $\mathrm{P}$ conditions.

In this study, cultivated soybean and wild soybean were used as the experimental materials. Under low $\mathrm{P}$ conditions, the change and migration of mineral nutrients between young and old leaves of wild soybean were explored by analyzing changes and differences in changes for ionomics in young and old leaves of two soybean varieties. Moreover, the transport and reuse of organic nutrients between young and old leaves of wild soybean were explored by comparing the changes and differences in changes for metabolomics in young and old leaves of two soybean varieties. Our study aims to reveal the physiological mechanism of wild soybean under low $\mathrm{P}$ conditions. This study can provide direct evidence for the function and metabolic regulation of small molecule metabolites in wild soybean under low P conditions, and offer a theoretical basis to breed new low $\mathrm{P}$ tolerant soybean varieties.

\section{Materials and methods}

Plant materials and growth conditions

Seeds of wild soybean ('Huinan06116') and cultivated soybean ('Jinong24') were kindly provided by the Jilin Academy of Agriculture Science, China. The mean temperature values in an outdoor experimental field at Northeast Normal University (Changchun, Jilin Province, China) were $26 \pm 2{ }^{\circ} \mathrm{C}$ and $18.5 \pm 1.5{ }^{\circ} \mathrm{C}$ during the day and night, respectively; and the relative humidity was $60.5 \%$. Seeds were sown in 14 -cm diameter pots with clean sand and then irrigated for germination. The seedlings were irrigated with Hoagland nutrient solution after the germination.

\section{$P$ treatment}

Wild soybean and cultivated soybean were randomly divided into two groups, with eight pots in each group: control and low P-treated group. Two seeds were sown in each pot, and only one seedling remained when the stress treatment began. The low $\mathrm{P}$ treatment began when the seedlings reached the third compound leaf stage. In the low P-treated group, wild soybean and cultivated soybean seedlings were irrigated with

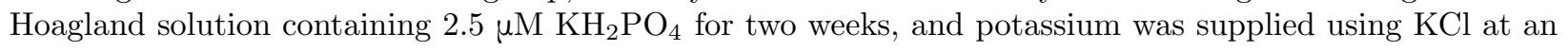


equal concentration as in low P Hoagland solution (pH5.8). In the control, seedlings were cultured under

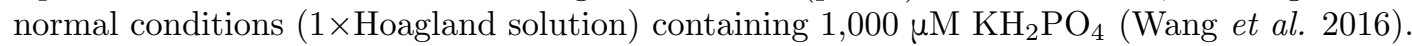

\section{Plant harvest}

The first two node leaves were collected from the top and bottom of the seedlings as young leaves and old leaves, respectively. At the end of low $\mathrm{P}$ treatment, young and old leaves of two soybean varieties were harvested from four randomly selected pots from eight replicates in each group to perform the metabolite analysis. These samples were immediately frozen in liquid nitrogen and stored in $-80{ }^{\circ} \mathrm{C}$. The remaining four pots of each group were used to determine ion content.

\section{Measurement of ion content}

Dried $50 \mathrm{mg}$ samples were placed into $15 \mathrm{~mL}$ centrifuge tube, then $4 \mathrm{~mL}$ deionized water was added, boiled for $40 \mathrm{~min}$, and soaked overnight. The samples were centrifuged at $3000 \times \mathrm{g}$ for $15 \mathrm{~min}$, and the supernatants were collected. The above steps were repeated twice again, without overnight, and finally, the volume was fixed to $15 \mathrm{~mL}$. An atomic absorption spectrophotometer (Super 990F; Beijing Purkinje General Instrument Co. Ltd, China) was used to determine cation concentrations (i.e., $\mathrm{Mn}^{2+}, \mathrm{K}^{+}, \mathrm{Na}^{+}, \mathrm{Mg}^{2+}, \mathrm{Ca}^{2+}, \mathrm{Zn}^{2+}, \mathrm{Fe}^{3+}$, and $\mathrm{B}^{3+}$ ). Ion chromatography (DX-300 ion chromatographic system, AS4A-SC chromatographic column, CDM-II electrical conductivity detector, mobile phase: $\mathrm{Na}_{2} \mathrm{CO}_{3} / \mathrm{NaHCO}_{3}=1.7 / 1.8 \mathrm{mM}$, Dionex) was used to determine anion contents (i.e., $\mathrm{Cl}^{-}, \mathrm{NO}_{3}{ }^{-}, \mathrm{H}_{2} \mathrm{PO}_{4}^{-}, \mathrm{SO}_{4}{ }^{2-}$ ). The data of ion contents were analyzed using SPSS statistical software, version 16 (Liu et al. 2019).

\section{Metabolites extraction}

After freeze-drying, 50 +- $1 \mathrm{mg}$ sample was transferred into a $2 \mathrm{~mL}$ Eppendorf tube, and 1,000 $\mu \mathrm{L}$ of precold extraction mixture (methanol/dH2O (v:v) $=3: 1$ ) and $10 \mu \mathrm{L}$ of ribitol were added, and then samples were vortexed for $30 \mathrm{~s}$. Samples were homogenized with a ball mill for $4 \mathrm{~min}$ at $35 \mathrm{~Hz}$ (JXFSTPRP-24, Jingxin Technology Co. Ltd., Shanghai, China), followed by ultrasonication for $5 \mathrm{~min}$ in ice water (YM-080S, Fangao Microelectronics Co. Ltd., Shenzhen, China). The samples were centrifuged at $4{ }^{\circ} \mathrm{C}$ for 15 min at 10,000 $\times$ g (Heraeus Fresco17, Thermo Fisher Scientific), and transferred $200 \mu \mathrm{L}$ supernatant into a $1.5 \mathrm{~mL}$ Eppendorftube. $60 \mu \mathrm{L}$ of samples each were mixed into QC (quality control) sample. After evaporation in a vacuum concentrator (LNG-T98, Hua Mei Biochemical Instrument Factory Co., Ltd., Taicang, China), 120 $\mu \mathrm{L}$ of methoxyamination hydrochloride $(20 \mathrm{mg} / \mathrm{mL}$ in pyridine) was added. After gently mixing, they were put into an oven and incubated at $80{ }^{\circ} \mathrm{C}$ for $30 \mathrm{~min}$ (DHG-9023A, Yiheng Scientific Instruments Co. Ltd., Shanghai, China). $120 \mu \mathrm{L}$ of BSTFA regent (1\% TMCS,v/v) was added to each sample, and the mixtures were derivatized at $70^{\circ} \mathrm{C}$ for $1.5 \mathrm{~h}$. The samples cooled to room temperature, and then $7 \mu \mathrm{L}$ of fatty acid methyl esters (FAMEs) (in chloroform) was added to the QC sample. All samples were then analyzed using a gas chromatograph (GC) coupled with a time-of-flight mass spectrometer (GC-TOF-MS).

\section{GC-TOF-MS analysis}

GC-TOF-MS analysis was performed using an Agilent 7890 GC coupled with a time-of-flight mass spectrometer. The system utilized a DB-5MS capillary column. $1 \mu \mathrm{L}$ aliquot of the sample was injected in splitless mode. Helium was used as the carrier gas. The front inlet purge flow was $3 \mathrm{~mL} \mathrm{~min}^{-1}$ and the gas flow rate through the column was $1 \mathrm{~mL} \mathrm{~min}{ }^{-1}$. The initial temperature was kept at $50{ }^{\circ} \mathrm{C}$ for $1 \mathrm{~min}$ and then raised to $310{ }^{\circ} \mathrm{C}$ at a rate of $10{ }^{\circ} \mathrm{C} \mathrm{min}{ }^{-1}$. This process lasted for eight minutes at $310 \mathrm{deg}$. The transfer line, ion source, and injection temperatures were 280,250 , and $280 \mathrm{deg}$, respectively. The energy was $-70 \mathrm{eV}$ in electron impact mode. The mass spectrometry data were acquired in full-scan mode with the $\mathrm{m} / \mathrm{z}$ range of 50-500 at a rate of 12.5 spectra per s after a solvent delay of 6.30 min (Zhao et al. 2019).

\section{Data processing and multivariate data analysis}

ChromaTOF software (versions 2.12, 2.22, 3.34; LECO, St. Joseph, MI, USA) was used for raw data preprocessing, including peak extraction, baseline adjustment, deconvolution, alignment, and integration. Moreover, the LECO-Fiehn Rtx5 database was used for metabolite identification by matching the mass 
spectrum and retention index (Tobiaset al. 2009). Then, features with at least an $80 \%$ missing value were removed, and the missing values were filled with half of the minimum positive value in the original data. Next, the data were filtered using the interquartile range (IQR), and the total mass of the signal integration area was normalized for each sample. The normalized data were imported into SIMCA-P 13.0 software package (Umetrics, Umea, Sweden, RRID: SCR_014688) to perform principal component analysis (PCA), partial least squares discriminant analysis (PLS-DA), orthogonal partial least squares discriminant analysis (OPLS-DA), and loading maps. Besides, variable importance values (VIP) were obtained through PLS-DA and OPLS-DA analyses. In addition, the differential metabolites were determined by Student's $t$-test $(p<0.05)$ and VIP (VIP $>1$ ) combined with similarity value $>700$, and then the metabolic pathways were constructed using Kyoto Encyclopedia of Genes and Genomes (KEGG) (http://www.genome.jp/keg, RRID: SCR_001120), and the pathway was analyzed using MetaboAnalyst website (http://http://www.metaboanalyst.ca, RRID: SCR_015539), which was based on changes in metabolite concentration compared to the corresponding control (Xia, Mandal, Sinelnikov, Broadhurst \& Wishart 2012; Yang, Zhang, Li \& Shi 2017).

\section{Results}

\section{Ionomics responses}

The principal component analysis (PCA) showed that the first principal component (PC1) explained $34.40 \%$ of the variance, and the ions with larger contribution rate were $\mathrm{B}^{3+}$ and $\mathrm{H}_{2} \mathrm{PO}_{4}{ }^{-}$. The second principal component (PC2) explained $29.30 \%$ of the variance, and $\mathrm{SO}_{4}{ }^{2-}, \mathrm{Ca}^{2+}$ and $\mathrm{Mg}^{2+}$ were the major contributors (Figure 1; Supp. Table S1). Under low $\mathrm{P}$ conditions, compared with the control, the contents of $\mathrm{Mn}^{2+}$, $\mathrm{Mg}^{2+}, \mathrm{Ca}^{2+}, \mathrm{Fe}^{3+}, \mathrm{NO}_{3}{ }^{-}$, and $\mathrm{SO}_{4}{ }^{2-}$ in the young leaves of wild soybean significantly increased $(p<0.01)$. The contents of $\mathrm{Mn}^{2+}$, and $\mathrm{SO}_{4}{ }^{2-}$ in the young leaves of cultivated soybean significantly increased $(p<$ $0.05)$, and the increases were less than that in wild soybean. The contents of $\mathrm{B}^{3+}$ and $\mathrm{H}_{2} \mathrm{PO}_{4}^{-}$in young leaves of two soybean varieties were decreased, and the decrease in cultivated soybean was higher than that in wild soybean. Compared with the control, under low $\mathrm{P}$ conditions, contents of $\mathrm{Mn}^{2+}, \mathrm{Na}^{+}, \mathrm{Mg}^{2+}, \mathrm{Ca}^{2+}$, $\mathrm{Fe}^{3+}, \mathrm{Cl}^{-}$, and $\mathrm{SO}_{4}{ }^{2-}$ in old leaves of wild soybean significantly increased. The contents of $\mathrm{Zn}^{2+}, \mathrm{B}^{3+}$, and $\mathrm{H}_{2} \mathrm{PO}_{4}{ }^{-}$in old leaves of two soybean varieties significantly decreased compared with the control, especially in old leaves of cultivated soybean (Figure 2).

\section{Metabolomics analysis}

Our PCA results showed that the factors affecting the metabolomics for wild and cultivated soybeans (Figure 3). PC1 explained $43.20 \%$ and $49.60 \%$ of the variance, respectively, and significant differences between young and old leaves were detected (Figure 3A and 3B). PC2 explained the difference between the control and low P conditions, explaining $21.50 \%$ and $17.30 \%$ of the variance, respectively (Figure $3 \mathrm{~A}$ and $3 \mathrm{~B}$ ). For wild soybean, L-malic acid, saccharic acid, Myo-inositol, and D-erythro-sphingosine greatly contributed to PC1, while malonic acid, 3-cyanoalanine, asparagine, phenylalanine, and glycine greatly contributed to PC2 (Figure 3C; Supp. Table S2). The contribution of metabolites in cultivated soybean to PC1 was dominated by shikimic acid, asparagine, and glycine; and malonic acid, gentiobiose, and glutaric acid were major contributors to PC2 (Figure 3D; Supp. Table S3). According to $p<0.05$, similarity $>700$ and VIP $>1$, we focused on the levels of 50 and 49 metabolites with significant changes in the young and old leaves of wild soybean and cultivated soybean, respectively (Table 1 and 2; Figure 4; Supp. Figure S1; Supp. Figure S2).

Under low P conditions, the contents of metabolites related to the TCA cycle in young and old leaves of wild soybean expressed an increasing trend, especially in young leaves of wild soybean, whereas oppositely in young and old leaves of cultivated soybean. Contents of citramalic acid and L-malic acid significantly increased in young leaves of wild soybean. However, contents of maleic acid and $\alpha$-ketoglutaric acid did not significantly change. Contents of L-malic acid and maleic acid in old leaves of wild soybean significantly increased but there was no impact on the contents of citramalic acid and $\alpha$-ketoglutaric acid. In cultivated soybean, methylmalonic acid and itaconic acid in young leaves were significantly decreased, and contents of methylmalonic acid, itaconic acid, citric acid, citramalic acid, and $\alpha$-ketoglutaric acid in old leaves were significantly declined under low $\mathrm{P}$ conditions. 
Under low $\mathrm{P}$ conditions, amino acids in the young and old leaves of wild soybean were higher than those under the control, including the aliphatic amino acids (e.g., glutamine, asparagine, glycine, and lysine), and aromatic amino acids (e.g., tyrosine, tryptophan, and phenylalanine). Moreover, these increases were higher in old leaves than those in young leaves compared with their respective control. However, amino acids in young leaves of cultivated soybean showed a decreasing trend, with decreasing content of aliphatic amino acids (e.g., aspartic acid, alanine, serine, and L-cysteine). Contents of aliphatic amino acids (glutamine, asparagine, and glycine) and aromatic amino acids (tryptophan and tyrosine) significantly increased in old leaves of cultivated soybean, but these increases were lower than those in the old leaves of wild soybean. Meanwhile, contents of 3-cyanoalanine, L-homoserine, $\beta$-alanine, and L-allothreonine in the young leaves of wild soybean increased by 3.09-, 0.68-, 0.48- and 0.85- fold, respectively; and increased by 4.43-, 1.86-, 0.14and 0.94-fold in old leaves, respectively. In cultivated soybean, contents of 3-cyanoalanine, L-homoserine, $\beta$-alanine, and L-allothreoninein young leaves increased by 0.01-, 0.91, 0.47- and 0.60-fold, respectively; and in the old leaves increased by 2.37-, 1.09-, 0.17- and 0.50-fold, respectively. Compared with the control, the enrichment of these four amino acids more in the young and old leaves of wild soybean was significantly higher than those in young and old leaves of cultivated soybean. Under low $\mathrm{P}$, contents of nitrogenous compounds in young and old leaves of wild soybean increased, among which contents of maleimide, tyramine, nicotinamide, and citrulline increased, especially in young leaves. Contents of maleimide and tyramine in young leaves of cultivated soybean decreased $(p<0.05)$, whereas there was no impact in old leaves $(p>$ 0.05). Compared with the control, polyols including phytosphingosine, Myo-inositol, D-erythro-sphingosine, and threitol increased in young leaves of wild soybean but decreased in old leaves. Contents of Myo-inositol, glycerol, and palatinitol increased in young leaves of cultivated soybean but decreased in old leaves. Compared with the control, sugars expressed an upward trend in young and old leaves of wild soybean under low $\mathrm{P}$ conditions, especially in young leaves. In young leaves of wild soybean, contents of 6-deoxy-D-glucose, xylose, and sedoheptulose (monosaccharides), maltose and sucrose (disaccharides), and melezitose (a trisaccharide) increased. In old leaves of wild soybean, contents of 6-deoxy-D-glucose, maltose, gentiobiose, and melezitose increased. In young leaves of cultivated soybean, monosaccharides including xylose, D-altrose, and sedoheptulose decreased, but maltose, gentiobiose, sucrose, and 1-Kestose increased, and increased in maltose and sucrose were less than that in young leaves of wild soybean. Compared with the control, activities offructose-6-phosphate, glucose-6-phosphate, 6-phosphogluconic acid, and 2, 6-diphosphate fructose decreased in young and old leaves of wild soybean under low $\mathrm{P}$ conditions, especially in old leaves, and which also decreased in young and old leaves of cultivated soybean, especially in young leaves. Under low $\mathrm{P}$ conditions, compared with the control, organic acid metabolites increased in old leaves of wild soybean but decreased in young leaves. Organic acid metabolites decreased both in young and old leaves of cultivated soybean. Contents of lactic acid, 4-hydroxybutyrate, nicotinic acid, adipic acid, and lactobionic acid significantly increased in old leaves of wild soybean $(p<0.01)$, whereas lactic acid, 4-hydroxybutyrate, nicotinic acid, adipic acid, lactobionic acid, $\alpha$-keto-isovaleric acid, saccharic acid, D-galacturonic acid, $\alpha$-ketobutyric acid, quinicacid, oxalic acid, and malonic acid decreased in young leaves. In cultivated soybean, contents of oxalic acid, malonic acid, 2-methylfumarate, and shikimic acid significantly decreased in old leaves. Moreover, contents of glycolic acid, $\alpha$-keto-isovaleric acid, saccharic acid, D-galacturonic acid, $\alpha$-ketobutyric acid, quinic acid, malonic acid, 2-methylfumarate, glutaric acid, and shikimic acid significantly decreased in young leaves.

\section{Discussion}

$\mathrm{P}$ is a necessary element for plant growth and development. It is an important way to reveal the mechanism of low P tolerance in wild soybean to study the transport and reuse of mineral nutrients, and organic matter between young and old leaves under low $\mathrm{P}$ conditions. There are dependence and balance between various elements in crops, and the deficiency of certain elements often affects the accumulation, transport, and metabolism of other mineral nutrients (Schachtman \& Shin 2007). Arabidopsis thaliana can increase the content of sulfur to synthesize sulfur lipids under low $\mathrm{P}$ conditions (Misson et al.2005). Phospholipids can be replaced by sulfur lipids to reduce the demand of membrane lipids for $\mathrm{P}$ (Vance 2003). The accumulation of appropriate concentrations of $\mathrm{Mg}^{2+}$ and $\mathrm{Fe}^{3+}$ in plants can promote photosynthesis because $\mathrm{Mg}^{2+}$ is an 
important component of chlorophyll, and $\mathrm{Fe}^{3+}$ is involved in the synthesis of chlorophyll and plays a key role in electron transport in the photosynthesis (Alderkamp, Dijken, Lowry, Connelly \& Arrigo 2015; Kirkby \& Mengel 1976; Kortessa \& Artemios 1997; Briat, Curie \& Gaymard 2007). Under low P conditions, the content of $\mathrm{SO}_{4}{ }^{2-}$ significantly increased in young and old leaves of wild soybean, especially in young leaves, and the increase was much higher than that in cultivated soybean. Moreover, contents of $\mathrm{Mg}^{2+}$ and $\mathrm{Fe}^{3+}$ significantly increased in young and old leaves of wild soybean under low $\mathrm{P}$ but decreased in cultivated soybean. This result suggested that the increase of $\mathrm{Mg}^{2+}$ and $\mathrm{Fe}^{3+}$ in wild soybean may help to enhance its photosynthesis and alleviate the damage caused by low $\mathrm{P}$ condition. Besides, the content of $\mathrm{H}_{2} \mathrm{PO}_{4}{ }^{-}$in wild soybean decreased less than that in cultivated soybean, and the decrease in young leaves was lower than that in old leaves under low $\mathrm{P}$, suggesting transportation of $\mathrm{H}_{2} \mathrm{PO}_{4}{ }^{-}$from old leaves to young leaves (Dieter, Kirkby, Peuke, Pate \& Wolfram 1997). Our result showed that $\mathrm{NO}_{3}{ }^{-}$significantly increased in young leaves of wild soybean but decreased in old leaves, indicating that amount of $\mathrm{NO}_{3}{ }^{-}$transported from old leaves to young leaves (Criado, Veliz, Roberts \& Caputo 2017). $\mathrm{NO}_{3}{ }^{-}$can be reduced and assimilated into amino acids and other nitrogen-containing substances, and they respond positively to abiotic stresses (Khan, Ali, Zandi, Mehmood \& Babar 2020). These results suggested that wild soybean might adapt to low P stress by increasing $\mathrm{SO}_{4}{ }^{2-}, \mathrm{Mg}^{2+}$, and $\mathrm{Fe}^{3+}$ and transferring $\mathrm{H}_{2} \mathrm{PO}_{4}{ }^{-}$and $\mathrm{NO}_{3}{ }^{-}$from old leaves to young leaves, which can supply the nutritional deficit caused by low $\mathrm{P}$ conditions.

Dry weight and number of soybean nodules are decreased under low P (Wang, Han, Qiao, Yan \& Li 2009). Our study showed that the quantity and quality of nodules decreased in two soybean varieties under low P, but there was no difference between the changes of two soybean varieties, suggesting that differences between them under low P may be related to the physiology, morphological structure, and intracellular metabolism. The TCA cycle is the best way with energy substances oxidized to produce energy in plants, and it plays an important role to tolerate adverse environmental conditions including salt stress and low nitrogen (Yang et al. 2017; Liu et al. 2019).Brassica napus and wheat can tolerate low $\mathrm{P}$ stress by the enhancement of the TCA cycle (Wang, Qin, Pan, Sun \& Song 2019; Yao, Sun, Xu, Zhang \& Liu 2011). The TCA cycle and its cofactor $\mathrm{Mg}^{2+}$ significantly increased in young and old leaves of wild soybean, especially in young leaves, but significantly decreased in young and old leaves of cultivated soybean. These results indicated that wild soybean might provide more energy for plant physiological and metabolic activities by strengthening the TCA cycle to tolerate low P.

Plants can adapt to different environmental stresses by regulating the distribution of photosynthetic products (Chen, Yin, Chen \& Pan 2013). For example, under drought, low phosphorus, and other abiotic stress conditions, plants can promote the transport of photosynthetic products to young tissues (Gu, Ding, Gao \& Xing 2010; Yuan et al. 2011). Sugars in plants can be used for energy metabolism and complex carbohydrate biosynthesis, which can be transported from mature and old leaves to young leaves, providing resources for the growth and development of young leaves (Assaf, Raz \& Fischer 2014; Hammond \& White 2008; Wolf 1993). Sucrose is the main form of carbohydrate transport and storage in higher plants (Yu, Wang, Zhu \& Jiang 2015). Under low $\mathrm{P}$ conditions, sucrose is increased less in source leaves than in young leaves in bean (Phaseolus vulgaris L.), suggesting that sucrose may be transported from source leaves to young leaves to maintain the growth of young leaves (Ciereszko \& Barbachowska 2000). In addition, sugars can act as a second messenger, regulating plant growth and development to adapt to abiotic stresses including drought, salt stress, and mineral nutrient deficiency (Hammond \& White 2008; Wang et al. 2019; Zhang et al. 2016). Sucrose is regarded as a P-starvation signal promoting the expression of phosphate-starvation inducible (PSI) genes under low $\mathrm{P}$, and these genes are involved in regulating the transport, distribution, and mobilization of inorganic phosphate $(\mathrm{Pi})$ between different organs, and then tolerate low $\mathrm{P}$ stress (Müller et al. 2015; Lei et al. 2011). Under low $\mathrm{P}$, compared with the control, sugars increased in young and old leaves of wild soybean, especially in young leaves, indicating that the transport of sugar metabolites from old to young leaves were promoted in wild soybean. Moreover, the accumulation of di- and tri-saccharides in young and old leaves of wild soybean can reduce the consumption of Pi during the phosphorylation of sugar metabolites and convert small phosphorylated metabolites into di- and tri-saccharides without P. This mechanism may be a strategy to save $\mathrm{Pi}$, and a strategy of osmotic protection for plants under stress, which can provide better tolerance 
to low $\mathrm{P}$ stress in wild soybean (Huang et al. 2008).

Hexose-phosphate metabolites are small phosphorylated metabolites containing phosphoesters. A large amount of organic $\mathrm{P}$ is present in small phosphorylated metabolites, which are roughly equivalent to those in RNA or phospholipids (Huang et al. 2008). Inactive tissues (e.g., old leaves) in plants can utilize acid phosphatase (APase) to liberate Pi from organic P containing phosphoesters (e.g., small phosphorylated metabolites, RNA, and phospholipids) and transport them to young organs, and these processes are enhanced under low P (Dieter et al. 1997; Kyla \& William 2015). Under low P conditions, Pi could be mobilized from the organic P pool of old leaves to adapt to low P stress in low P-tolerant Akamaic (Dissanayaka, Nishida, Tawaraya \& Wasaki 2018); suggesting that young leaves are the main sink and assimilation organ of Pi (Dieter et al.1997). Hexose-phosphate metabolites in young leaves decreased less than that in old leaves of wild soybean; suggesting that Pi might be mobilized from hexose-phosphate metabolites in wild soybean old leaves and then transported to young leaves to maintain the growth under low P. However, in cultivated soybean young leaves and old leaves, hexose-phosphate metabolites decreased more in young leaves than in old leaves, and the reasons for such decreases in young leaves of cultivated soybean need further study.

Protein synthesis is inhibited, and the degradation protein is promoted under low $\mathrm{P}$ (Misson et al. 2005; $\mathrm{Wu}$ et al. 2003). Moreover, the inhibition of protein synthesis under low $\mathrm{P}$ is considered an energy-saving strategy (Schlüter et al. 2013). Under salt stress, low N and P, protein degradation in old leaves is promoted, and the amino acids are transported to the young tissues in the form of glutamine and asparagine (Khanet al. 2020; Xiao, Cui, Lu, Han \& Yang 2019). The accumulated amino acids can enhance the stress resistance of young tissues by promoting detoxification of reactive oxygen species (ROS), adjusting $\mathrm{pH}$, and making osmotic adjustments (Zhou et al. 2020). Glycine is a significant intermediate in photorespiration. Under low $\mathrm{P}$, glycine and serine are significantly increased in plant leaves; indicating that the photorespiration is enhanced (Ganie et al. 2015). In sunflower and soybean leaves, photorespiration might be enhanced under low P (Agnieszka \& Anna 1997; Jacob \& Lawlor 1993). Pi released by the photorespiration can be utilized by photosynthesis under low $\mathrm{P}$, which promotes $\mathrm{Pi}$ recycle in maize leaves, and toleration to low $\mathrm{P}$ stress (Kewei, Hanhan, Peilin, Huan \& Ts 2014; Pant et al. 2014). Our results indicated that amino acids such as asparagine, glutamine, and glycine significantly accumulated in young and old leaves of wild soybean, especially in old leaves. This result suggested that protein degradation and synthesis under low P might be enhanced and inhibited in wild soybean old leaves, respectively, and amino acids in old leaves might be transported to young leaves to maintain the growth. Plants are damaged by ammonia toxicity and oxidative stress caused by ROS under low P (Chen, Zhao, Ding \& Xu 2015; Rufty, Israel, Volk, Jinshu \& Tongmin 1993). Nitrogenous compounds such as tyramine and citrullinecan alleviate the damage caused by ammonia toxicity and oxidative stress to plants, and which was highly accumulated in young and old leaves of wild soybean, especially in young leaves, indicating that young and old leaves of wild soybean can alleviate damages caused by low P by increasing contents of tyramine and citrulline (Akashi, Miyake \& Yokota 2001; Ganie et al. 2015; Huang et al. 2008; Pant et al. 2014; Yen \& Kao 1993).

\section{Conclusion}

Under low P conditions, the growth and survival of wild soybean depend on the regulation and interaction of physiology and metabolism, and the transportation and reuse of nutrients between young and old leaves. In this study, the ionomics of young and old leaves of two soybean varieties under low $\mathrm{P}$ showed that wild soybean can improve the tolerance to low $\mathrm{P}$ by promoting the accumulation of some mineral nutrients including $\mathrm{Mg}^{2+}$, $\mathrm{Fe}^{3+}$, and $\mathrm{SO}_{4}{ }^{2-}$ in young and old leaves, and promoting the transportation of $\mathrm{NO}_{3}{ }^{-}$and $\mathrm{H}_{2} \mathrm{PO}_{4}{ }^{-}$from old leaves to young leaves. Based on the metabonomics analysis of young and old leaves in wild soybean and cultivated soybean under low $\mathrm{P}$, the mechanism of tolerance to low $\mathrm{P}$ for wild soybean can be presented as follows: enhance the TCA cycle metabolism in young and old leaves, and increase energy supply; increase the sugar metabolite content including maltose and sucrose and amino acid metabolites such as asparagine, glutamine, and glycine in young and old leaves, and promote the transport of sucrose, amino acids (e.g., asparagine and glutamine) from old leaves to new leaves; mobilize Pi from hexose-phosphate metabolites of old leaves and transported Pi to young leaves; and alleviate the damage caused by low $\mathrm{P}$ through the 
accumulation of nitrogenous compounds in young and old leaves. Our results revealed the mechanism of low $\mathrm{P}$ tolerance in wild soybean and provided a theoretical basis for the cultivation of low $\mathrm{P}$ tolerant soybean varieties.

\section{Acknowledgment}

This work was supported by the National Natural Science Foundation of China (No. 32072012) and Natural Science Foundation of Jilin Province, China (No. 20200201134JC).

\section{RRID}

KEGG: http://www.genome.jp/kegg, RRID: SCR_001120

Metaboanalyst: http://http://www.metaboanalyst.ca, RRID: SCR_015539

SIMCA-P 13.0: RRID: SCR_014688

\section{Conflict of interest}

The authors declare no competing interests.

\section{Contributions}

WYS, RG and LXS designed the study. WYS, YXZ, JC, NNM, SJG and DPL performed the research. WYS analyzed the data, and WYS, RG, DPL, TZ and LXS wrote the manuscript. All authors reviewed the manuscript.

\section{References}

Agnieszka K. \& Anna M. R. (1997) The role of Pi recycling processes during photosynthesis in phosphatedeficient bean plants. Journal of Experimental Botany 48(312), 1461-1468.

Akashi K., Miyake C. \& Yokota A. (2001) Citrulline, a novel compatible solute in drought-tolerant wild watermelon leaves, is an efficient hydroxyl radical scavenger. FEBS Letters 508(3),438-442.

Alderkamp A. C., Dijken G. L. V., Lowry, K. E., Connelly T. L. \& Arrigo K. R. (2015) Fe availability drives phytoplankton photosynthesis rates during spring bloom in the Amundsen Sea Polynya, Antarctica.Elementa: Science of the Anthropocene 3, 000043.

Assaf D., Raz A. \& Fischer A. M. (2014) Senescence, nutrient remobilization, and yield in wheat and barley. Journal of Experimental Botany 65(14), 3783-3798.

Balemi T. (2011) Effect of phosphorus (P) nutrition and leaf age on physiological growth parameters in a P-inefficient potato genotype. Journal of Horticultural Science and Biotechnology 86(4), 384-390.

Briat J. F., Curie C. \& Gaymard F. (2007) Iron utilization and metabolism in plants. Current Opinion in Plant Biology10(3), 276-282.

Brown L. K., George T. S., Barrett G. E., Stephen F. H. \& Philip J. W. (2013) Interactions between root hair length and arbuscular mycorrhizal colonisation in phosphorus deficient barley (Hordeum vulgare ).Plant and Soil 372(1-2), 195-205.

Chen S., Zhao H., Ding G. \& Xu F. (2015) Genotypic differences in antioxidant response to phosphorus deficiency in Brassica napus. Plant and Soil 391, 19-32.

Chen Y., Yin P.D., Chen W. \& Pan W. J. (2013) Progress of mechanism model in plant photosynthate allocation. Plant Physiology Journal49(5), 425-436.

Ciereszko I. \& Barbachowska A. (2000) Sucrose metabolism in leaves and roots of bean (Phaseolus vulgaris L.) during phosphate deficiency. Journal of Plant Physiology 156(5), 640-644. 
Dodds W. K., Johnson K. R. \& Priscu J. C. (1989) Simultaneous nitrogen and phosphorus deficiency in natural phytoplankton assemblages: theory, empirical evidence, and implications for lake management. Lake E Reservoir Management 5(1), 21-26.

Crafts-Brandner S. J. (1992) Phosphorus nutrition influence on leaf senescence in soybean. Plant Physiology 98(3),1128-1132.

Criado M. V., Veliz C. G., Roberts I. N. \& Caputo C. (2017) Phloem transport of amino acids is differentially altered by phosphorus deficiency according to the nitrogen availability in young barley plants. Plant Growth Regulation 82(1), 1-10.

Dieter J. W., Kirkby E. A., Peuke A. D., Pate J. S. \& Wolfram H. (1997) Effects of P deficiency on assimilation and transport of nitrate and phosphate in intact plants of castor bean (Ricinus communis L.). Journal of Experimental Botany 48, 75-91.

Ding Z., Jia S., Wang Y., Xiao J. \& Zhang Y. (2017) Phosphate stresses affect ionome and metabolome in tea plants. Plant Physiology and Biochemistry 120, 30-39

Dissanayaka D. M. S. B., Nishida S., Tawaraya K. \&Wasaki J. (2018) Organ-specific allocation pattern of acquired phosphorus and dry matter in two rice genotypes with contrasting tolerance to phosphorus deficiency. Soil Science and Plant Nutrition 64(3),282-290.

Fredeen A. L., Raab T. K. \& Terry R. N. (1990) Effects of phosphorus nutrition on photosynthesis in Glycine Max (L.)Merr..Planta 181(3), 399-405.

Fu L. B., Shen Q. F., Liu H., Kuang, Yu J., Wu D. \& Zhang G. (2018) Metabolite profiling and gene expression of $\mathrm{Na} / \mathrm{K}$ transporter analyses reveal mechanisms of the difference in salt tolerance between barley and rice. Plant Physiology \& Biochemistry 130, 248-257.

Ganie A. H., Ahmad A., Pandey R., Aref I. M., Yousuf P. Y., Ahmad S. \& Iqbal M. (2015) Metabolite profiling of low-p tolerant and low-p sensitive maize genotypes under phosphorus starvation and restoration conditions. Plos One 10(6), e0129520.

Gu Y. F., Ding S. Y., Gao Z. Y. \& Xing Q. (2010) The pattern of photosynthate partitioning in droughtstressed winter wheat and its relationship with yield. Acta Ecologica Sinica 30(5),1167-1173.

Guo R., Shi L. X., Jao Y., Li M. X., Zhong X. L., Gu F.X., Liu., Xia X. \& Li H. Ru. (2018) Metabolic responses to drought stress in the tissues of drought-tolerant and drought-sensitive wheat genotype seedlings. Aob Plants 10(2), 16 .

Guo R., Shi L. X., Yang C. W., Yan C. R., Zhong X. L., Liu Q., Xia X. \&Li H. R. (2016) Comparison of ionomic and metabolites response under alkali stress in old and young leaves of cotton (Gossypium hirsutum L.) Seedlings. Frontiers in Plant Science 7,1785.

Hammond J. P. \& White P. J. (2008) Sucrose transport in the phloem: integrating root responses to phosphorus starvation. Journal of Experimental Botany 59(1), 93-109.

Hillenmeyer M. E., Ericson E., Davis R. W., Nislow C., Koller D. \& Giaever G. (2010) Systematic analysis of genome-wide fitness data in yeast reveals novel gene function and drug action. Genome Biology11 (3), $362-365$.

Huang C. Y., Roessner U., Eickmeier I., Genc Y., Damien C.L., Shirley N., Langridge P. \& Bacic A. (2008) Metabolite profiling reveals distinct changes in carbon and nitrogen metabolism in phosphate-deficient barley plants (Hordeum vulgare L.).Plant $E$ Cell Physiology 49(5), 691-703.

Jacob J. \&Lawlor D. W. (1993) Extreme phosphate deficiency decreases the in vivo $\mathrm{CO}_{2} / \mathrm{O}_{2}$ specificity factor of Ribulose 1,5-bisphosphate carboxylase-oxygenase in intact leaves of sunflower. Journal of Experimental Botany 44(28), 1635-1641. 
Kewei Z., Hanhan L., Peilin T., Huan C. \&Ts. B. G. (2014) Comparative proteomic analyses provide new insights into low phosphorus stress responses in maize leaves. Plos One 9(5), e98215.

Khan N., Ali S., Zandi P., Mehmood A. \& Babar A. (2020) Role of sugars, amino acids and organic acids in improving plant abiotic stress tolerance. Pakistan Journal of Botany 52(2), 1-9.

Kirkby E. A. \&Mengel K. (1976) The role of magnesium in plant nutrition. Journal of Plant Nutrition and Soil Science139(2), 209-222.

Kortessa D. T. \&Artemios B. (1997) Effects of light, magnesium and sucrose on leaf anatomy, photosynthesis, starch and total sugar accumulation, in kiwifruit cultured in vitro. Plant Cell Tissue $\mathscr{E}$ Organ Culture 47(2), $127-134$.

Krmer S. \& Green D. M. (2000) Acid and alkaline phosphatase dynamics and their relationship to soil microclimate in a semiarid woodland.Soil Biology $\mathcal{E}$ Biochemistry 32(2), 179-188.

Kyla S. \& William P. (2015) Molecular mechanisms of phosphorus metabolism and transport during leaf senescence. Plants4(4), 773-798.

Lei M., Liu Y., Zhang B., Zhao Y., Wang X., Zhou Y., Raghothama K. G. \& Liu D. (2011) Genetic and genomic evidence that sucrose is a global regulator of plant responses to phosphate starvation in Arabidopsis.Plant Physiology 156, 1116-1130.

Liu Y., Li M. X., Xu J. S., Liu. X. Y., Wang S. Y. \& Shi L. X. (2019) Physiological and metabolomics analyses of young and old leaves from wild and cultivated soybean seedlings under low-nitrogen conditions. BMC Plant Biology 19 (6), 562-572.

Misson J., Raghothama K. G., Jain A., Jouhet J., Block M. A., Bligny R., Ortet P., Creff A., Somerville S., Rolland N. (2005) A genome-wide transcriptional analysis using Arabidopsis thaliana Affymetrix gene chips determined plant responses to phosphate deprivation.Proceedings of the National Academy of Sciences USA 102,11934-11939.

Müller J., Victoria G., Karsten N. \& Christian Z. (2015) Metabolic adaptations of white lupin roots and shoots under phosphorus deficiency.Frontiers in Plant Sience 6, 1014.

Pant B. D., Pant P., Erban A., Huhman D., Kopk J. \& Scheible W. (2014) Identification of primary and secondary metabolites with phosphorus status-dependent abundance in Arabidopsis, and of the transcription factor PHR1 as a major regulator of metabolic changes during phosphorus limitation. Plant, Cell $\mathscr{E}$ Environment 38(1), 172-187.

Richardson A. E., Lynch J. P., Ryan P. R., Delhaize E., Smith F. A. Smith S. E., Harvey P. R., Ryan M, H., Veneklaas E, J., Lambers H., Oberson A., Culvenor R. A. \& Simpson R. J. (2011) Plant and microbial strategies to improve the phosphorus efficiency of agriculture.Plant and Soil 349(1-2), 121-156.

Rufty T. W., Israel D. W., Volk R. J., Jinshu Q. \&Tongmin S. A. (1993) Phosphate regulation of nitrate assimilation in soybean. Journal of Experimental Botany 44(262), 879-891.

Runge-Metzger A. (1995) Closing the cycle: obstacles to efficient P management for improved global security. Phosphorus in the Global Environment: Transfers, Cycles and Management. 27-42.

Schachtman D. P. \& Shin R. (2007) Nutrient sensing and signaling: NPKS. Annual Review of Plant Biology $\mathbf{5 8 ( 1 )}, 47-69$.

Schlüter U., Colmsee C., Scholz U., Bräutigam A., Weber A. PM., Zellerhoff N., Bucher M. \& Sonnewald U. (2013) Adaptation of maize source leaf metabolism to stress related disturbances in carbon, nitrogen and phosphorus balance. BMC Genomics 14(1),442.

Tobias K., Gert W., Yup L. D., Yun L., Mine P. \& Oliver F. (2009) FiehnLib: mass spectral and retention 
index libraries for metabolomics based on quadrupole and time-of-flight gas chromatography/mass spectrometry. Anal Chem 81(24), 10038-10048.

Vance C. P., Claudia Uhde-Stone \& Allan D. L. (2010) Phosphorus acquisition and use: critical adaptations by plants for securing a nonrenewable resource. New Phytologist 157(3), 423-447.

Vance, C. (2003) Phosphorus acquisition and use: critical adaptations by plants securing a nonrenewable resource. New Phytologist 157(3), 423-447.

Wang J., Qin Q., Pan J., Sun L. \& Song K. (2019) Transcriptome analysis in roots and leaves of wheat seedlings in response to low-phosphorus stress. Scientific Reports 9(1), 19802.

Wang Q., Wang J., Yang Y., Du W., Zhang D., Yu D. \& Chen H. (2016) A genome-wide expression profile analysis reveals active genes and pathways coping with phosphate starvation in soybean. BMC Genomics $\mathbf{1 7}(\mathbf{1}), 192$.

Wang S. Q., Han X. Z., Qiao Y. F., Yan J. \& Li X. H. (2009) Nodule growth, nodulation and nitrogen as affected by P deficiency stress.Soybean Science 28(6), 1000-1003.

Wang X. X., Guo R., Li M. X., Liu Y., Zhao M. L., Fu H., Liu X. Y., Wang S.Y. \& Shi L. X. (2019) Metabolomics reveals the drought-tolerance mechanism in wild soybean (Glycine soja). Acta Physiologiae Plantarum 41(9), 161.

Wolf S. (1993) Effect of leaf age on photosynthesis, carbon transport and carbon allocation in potato plants. Potato Research36(3), 253-262.

Wu P., Ma L., Hou X., Wang M., Wu Y., Liu F. \&Deng X. W. (2003) Phosphate starvation triggers distinct alterations of genome expression in Arabidopsis roots and leaves. Plant Physiology132(3), 1260-1271.

Xia J., Mandal R., Sinelnikov I. V., Broadhurst D. \&Wishart D. S. (2012) MetaboAnalyst 2.0-a comprehensive server for metabolomic data analysis. Nucleic Acids Res 40, 127-133.

Xiao C., Cui X., Lu H., Han L. \& Yang C. (2019) Comparative adaptive strategies of old and young leaves to alkali-stress in hexaploid wheat.Environmental and Experimental Botany 171, 103955.

Xu Z. G., He Y., Yan B. X. \& Song C. C. (2007) Response of wetland plants to nitrogen and phosphorus inputs. Research of Environmental Sciences 20(1), 64-68.

Yang D. S., Zhang J., Li M. X. \&Shi L. X. (2017). Metabolomics analysis reveals the salt tolerant mechanism in Glycine soja .Journal of Plant Growth Regulation 36(2), 460-471.

Yao Y., Sun H., Xu F., Zhang X. \& Liu S. (2011) Comparative proteome analysis of metabolic changes by low phosphorus stress in twoBrassica napus genotypes. Planta 233(3), 523-537.

Yen G. C. \& Kao H. H. (1993) Antioxidative effect of biogenic amine on the peroxidation of linoleic acid. Journal of the Agricultural Chemical Society of Japan 57(1), 115-116.

Yu X. C., Wang J., Zhu M. Y. \& Jiang J. (2015) Molecular mechanism of carbohydrate metabolism participation in tomato response to low phosphorus stress. Molecular Plant Breeding 13(12),2833-2842.

Yuan S., Li C. J., Peng Z. P., Peng Y. F., Wang H. \& Zhang L. J. (2011) Effects of phosphorus on the plant growth, phosphorus cycling and distribution in different maize cultivars. Plant Nutrition and Fertilizer Science 17(2), 310-316.

Zhang J., Yang D. S., Li M. X. \& Shi L. X. (2016) Metabolic profiles reveal changes in wild and cultivated soybean seedling leaves under salt stress. Plos One 11(7), e0159622.

Zhao M. L., Guo R., Li M. X., Liu Y., Wang X. X., Fu H., Wang S. Y., Liu X. Y. \& Shi L. X. (2019) Physiological characteristics and metabolomics reveal the tolerance mechanism to low nitrogen in Glycine sojaleaves. PhysiologiaPlantarum 168 (4), 819-834. 
Zhou T., Yue C. P., Huang J. Y., Cui, J. Q., Liu, Y., Wang W. M., Tian C. \& Hua Y. P. (2020) Genomewide identification of the amino acid permease genes and molecular characterization of their transcriptional responses to various nutrient stresses in allotetraploid rapeseed. BMC Plant Biology 20, 151.

Table 1. Changes of low $\mathrm{P}$ condition on metabolite content in young and old leaves of wild soybean ${ }^{\mathrm{a}}$.

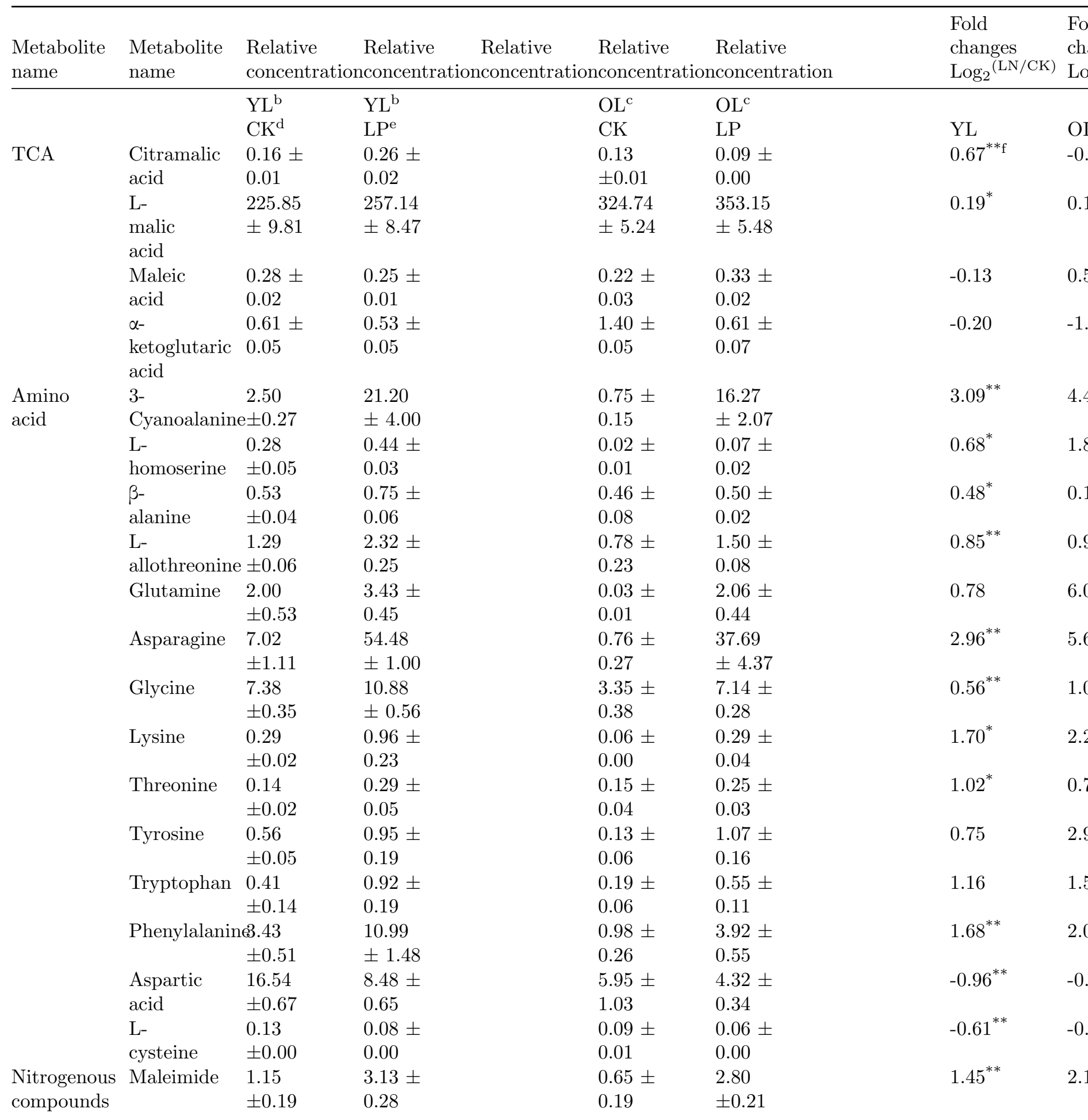




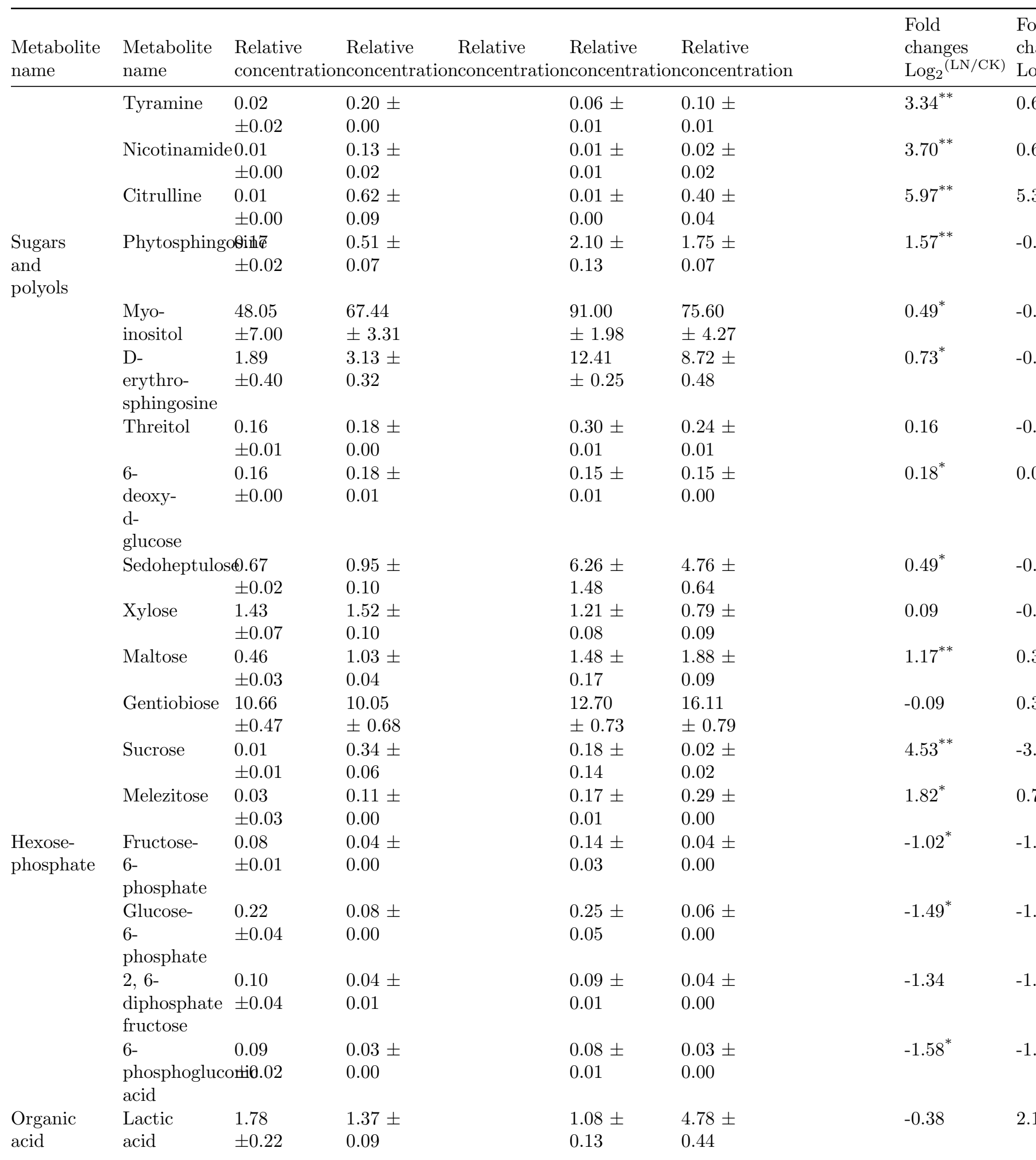




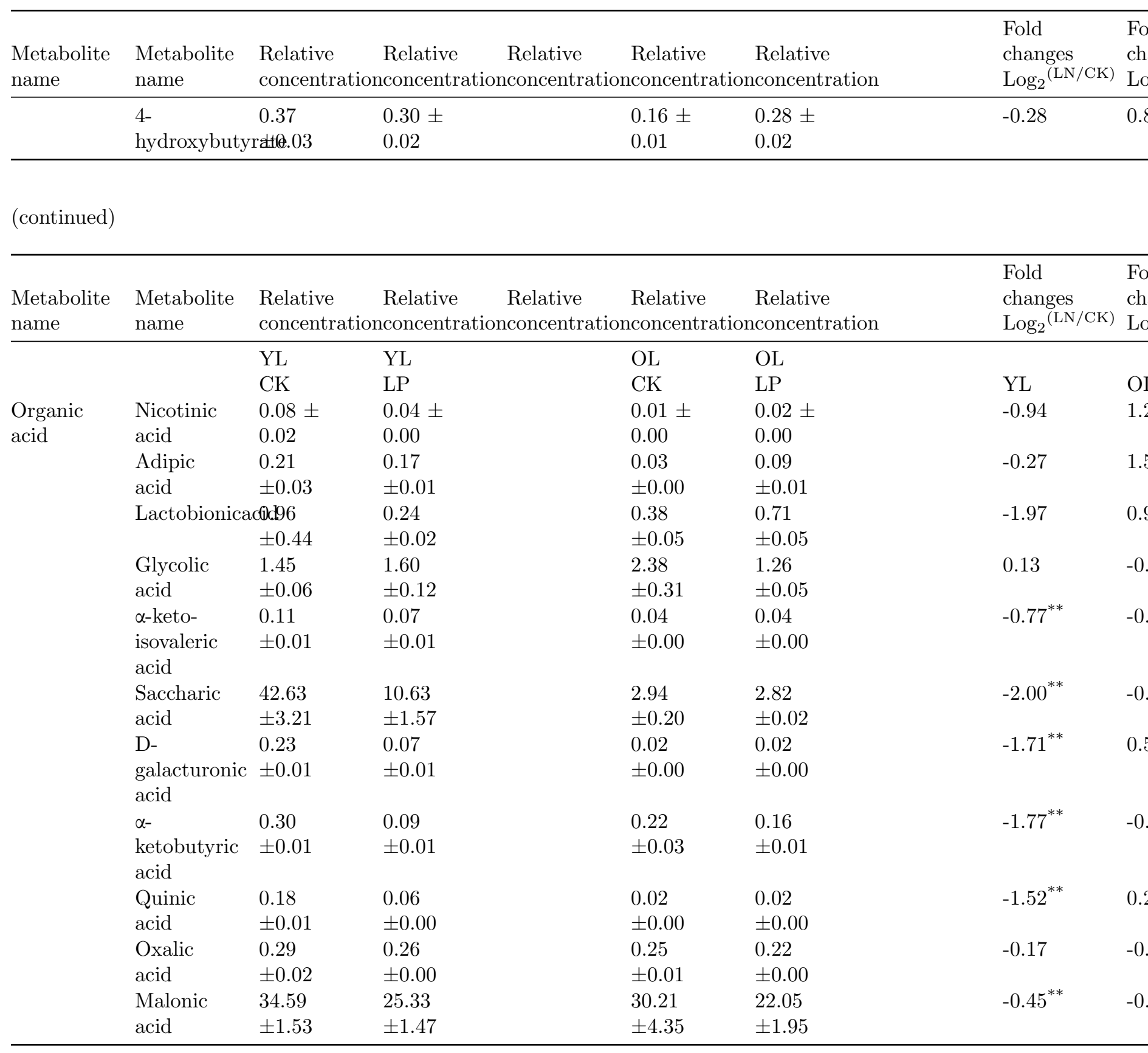

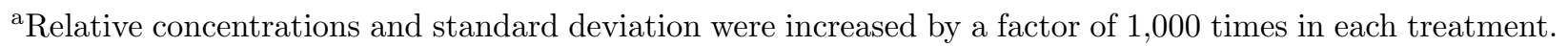
Values were presented as the mean \pm standard error of four biological replicates.

${ }^{b}$ YL, young leaves

${ }^{\mathrm{c}} \mathrm{OL}$, old leaves

${ }^{\mathrm{d}} \mathrm{CK}$, control treatment

${ }^{\mathrm{e}} \mathrm{LP}$, low $\mathrm{P}$ condition 
$\mathrm{f}^{*}$ and $^{* *}$ indicate significant $(p<0.05)$ and highly significant differences $(p<0.01)$, respectively.

Table 2. Changes of low $\mathrm{P}$ condition on metabolite content in young and old leaves of cultivated soybean ${ }^{\mathrm{a}}$.

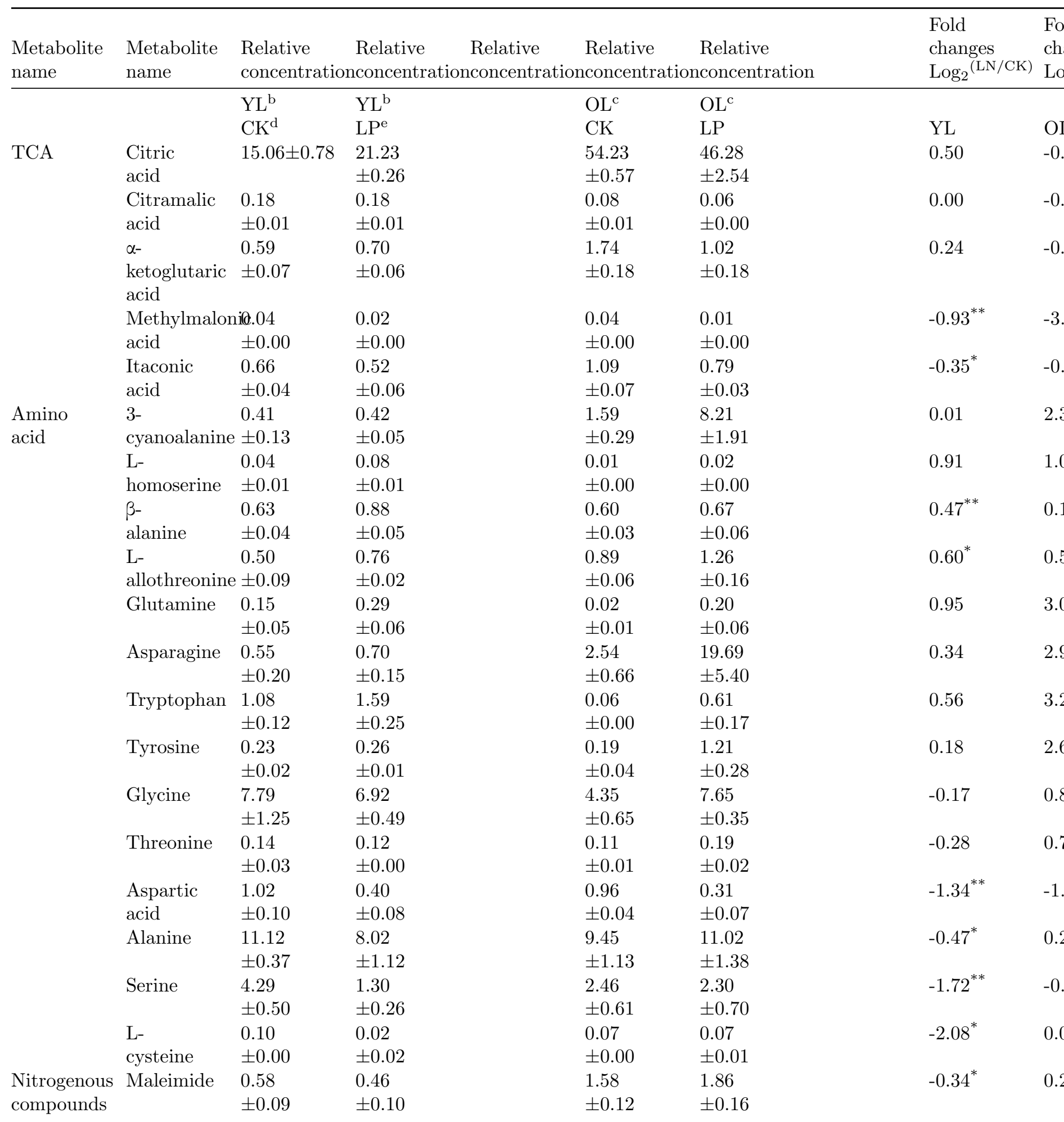




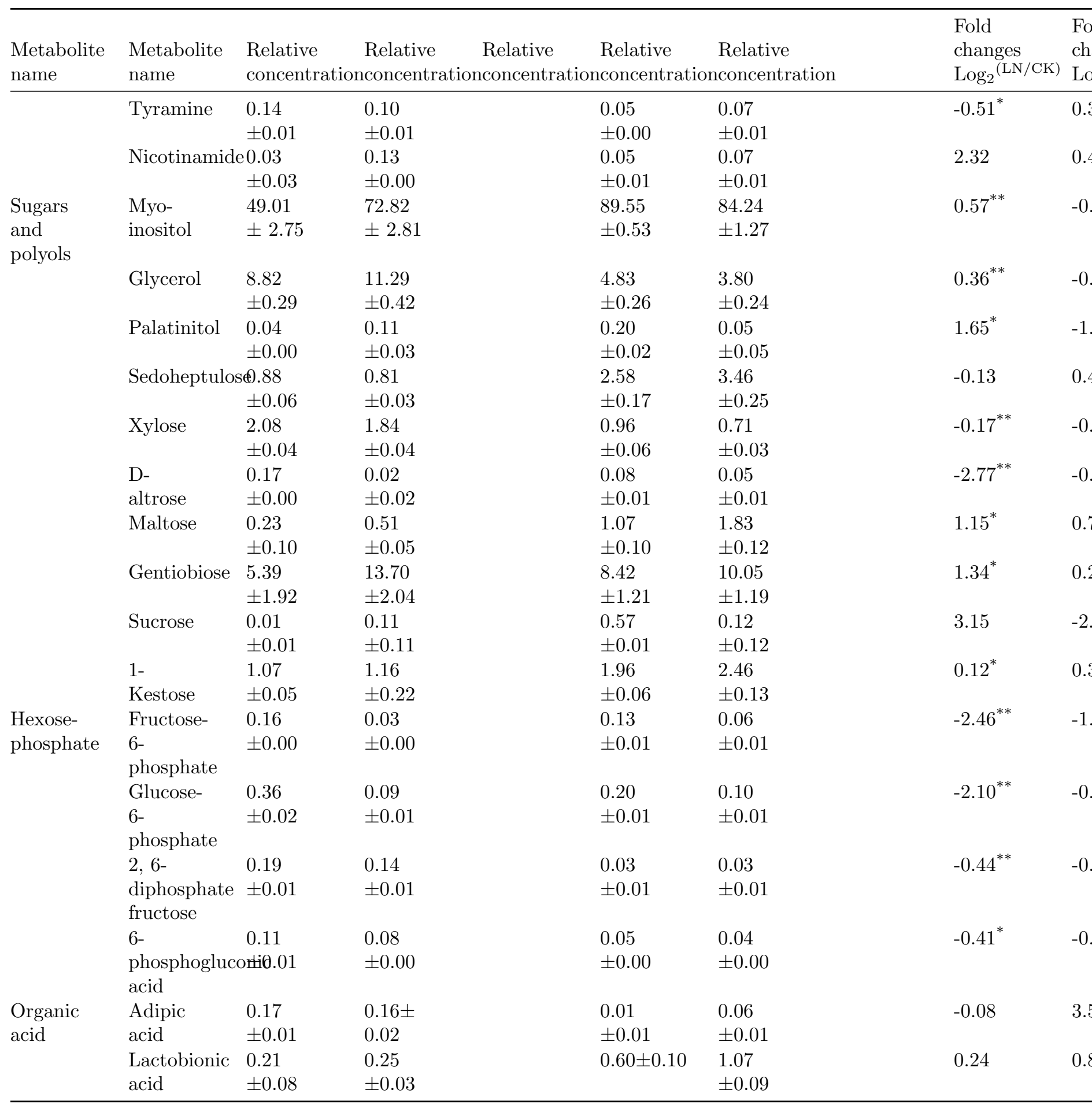

(continued) 


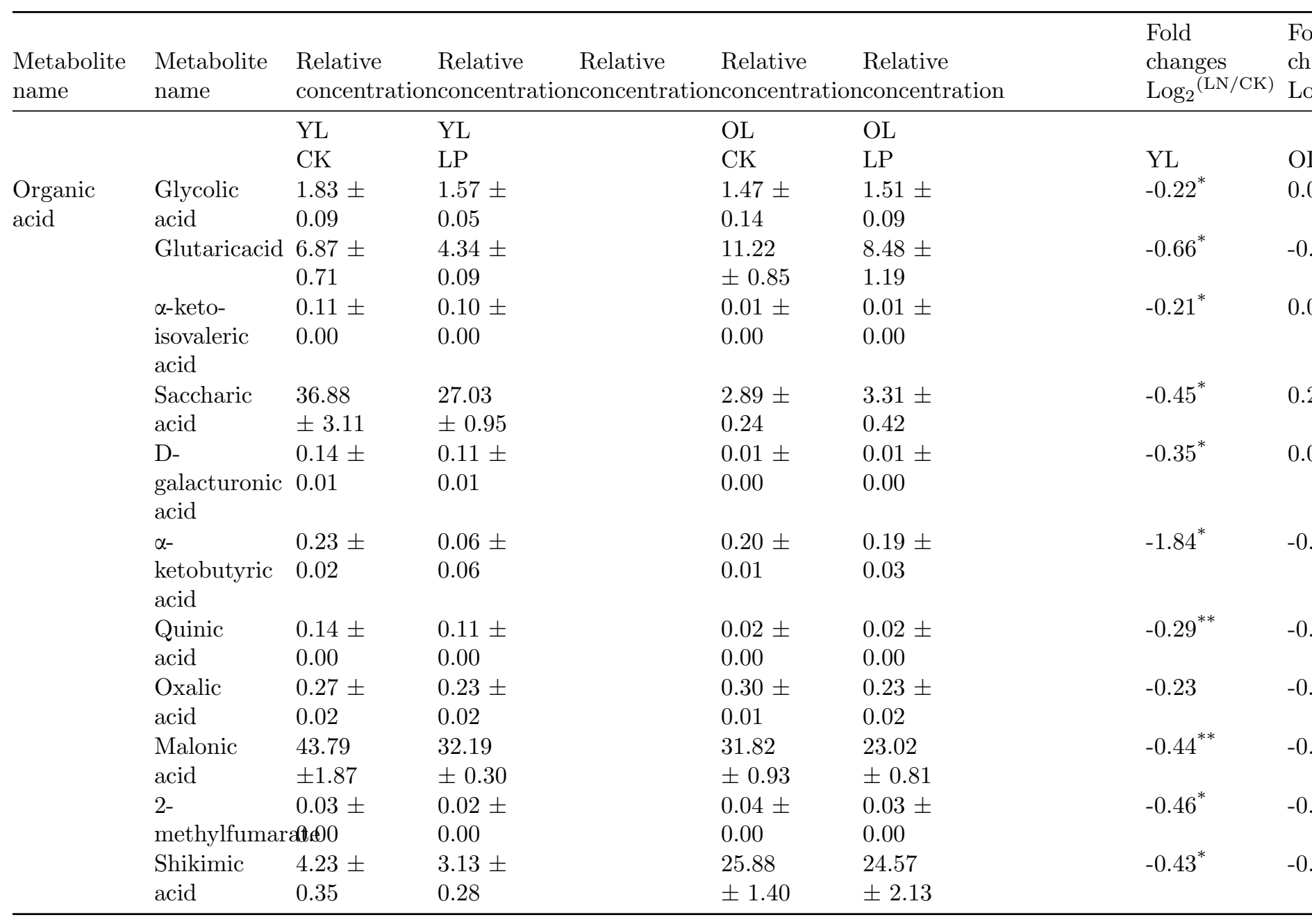

${ }^{\text {a }}$ Relative concentrations and standard deviation were increased by a factor of 1,000 times in each treatment. Values were presented as the mean \pm standard error of four biological replicates.

${ }^{\mathrm{b}} \mathrm{YL}$, young leaves

${ }^{\mathrm{c}} \mathrm{OL}$, old leaves

${ }^{\mathrm{d}} \mathrm{CK}$, control treatment

${ }^{\mathrm{e}} \mathrm{LP}$, low P condition

$\mathrm{f}^{*}{ }^{*} \mathrm{and}^{* *}$ indicate significant $(p<0.05)$ and highly significant differences $(p<0.01)$, respectively.

\section{Figure legends}

Figure 1. PCA of ionomic profiles and loading plots of ionomics in wild soybean and cultivated soybean. (A) PCA of wild soybean and cultivated soybean; (B) loading plot of wild soybean and cultivated soybean; GM, cultivated soybean; GS, wild soybean; YL, young leaves; OL, old leaves; CK, control treatment; LP, low $\mathrm{P}$ condition.

Figure 2. The change of ion contents in young and old leaves of two soybean varieties under low $\mathrm{P}$ condition and control condition. (A) $\mathrm{Ca}^{2+}$; (B) $\mathrm{H}_{2} \mathrm{PO}_{4}^{-}$; (C) $\mathrm{K}^{+}$; (D) $\mathrm{Mg}^{2+}$; (E) $\mathrm{NO}_{3}^{-}$; (F) $\mathrm{SO}_{4}{ }^{2-}$; (G) $\mathrm{B}^{3+}$; (H) $\mathrm{Cl}^{-}$; 
(I) $\mathrm{Fe}^{3+}$; (J) $\mathrm{Mn}^{2+}$; (K) $\mathrm{Na}^{+}$; (L) $\mathrm{Zn}^{2+}$. GM, cultivated soybean; GS, wild soybean; CK, control treatment; LP, low P condition; YL, young leaves; OL, old leaves. The values are the means +- SE of four biological replicates; ${ }^{*}$ and ${ }^{* *}$ indicate significant $(p<0.05)$ and highly significant $(p<0.01)$ differences, respectively.

Figure 3. PCA of metabolic profiles and loading plots of metabolites in two soybean varieties. (A) PCA of wild soybean; (B) PCA of cultivated soybean; (C) loading plot of wild soybean; (D) loading plot of cultivated soybean. GM, cultivated soybean; GS, wild soybean; CK, control treatment; LP, low P condition; YL, young leaves; OL, old leaves.

Figure 4. Changes in the metabolic pathways of young and old leaves in the two soybean varieties. Suggested changes in the metabolic network in soybean seedlings under low P condition using a partial least squarediscriminant analysis (PLS-DA).GM, cultivated soybean; GS, wild soybean; YL, young leaves; OL, old leaves.

\section{Supporting Information}

Supp.TableS1. The contribution of ions in young and old leaves of two soybean varieties to the first principal component (PC1) and the second principal component (PC2).

Supp.Table S2. The contribution of metabolites in young and old leaves of wild soybean to the first principal component (PC1) and the second principal component (PC2).

Supp.Table S3. The contribution of metabolites in young and old leaves of cultivated soybean to the first principal component (PC1) and the second principal component (PC2).

Supp. Figure S1. Total ion current chromatograms of young and old leaves of wild soybean extracts obtained from GC-MS. A: GS-YL-CK; B: GS-YL-LP; C: GS-OL-CK; D: GS-OL-LP. GS, wild soybean; CK, control treatment; LP, low P condition; YL, young leaves; OL, old leaves.

Supp. Figure S2. Total ion current chromatograms of young and old leaves of cultivated soybean extracts obtained from GC-MS. A: GM-YL-CK; B: GM-YL-LP; C: GM-OL-CK; D: GM-OL-LP.GM, cultivated soybean; CK, control treatment; LP, low P condition; YL, young leaves; OL, old leaves.
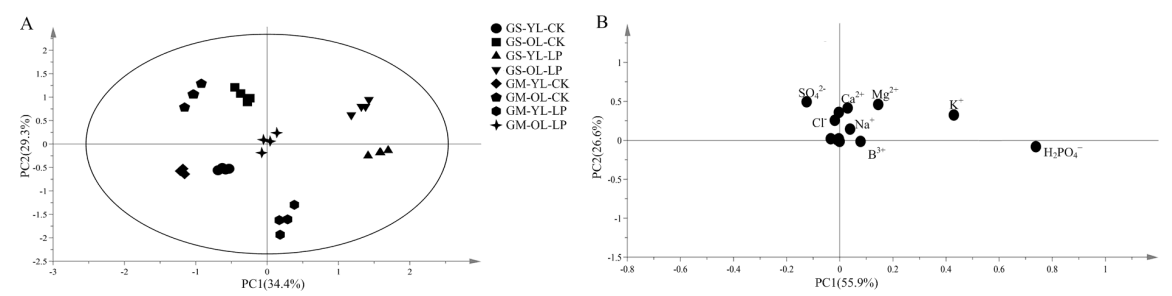


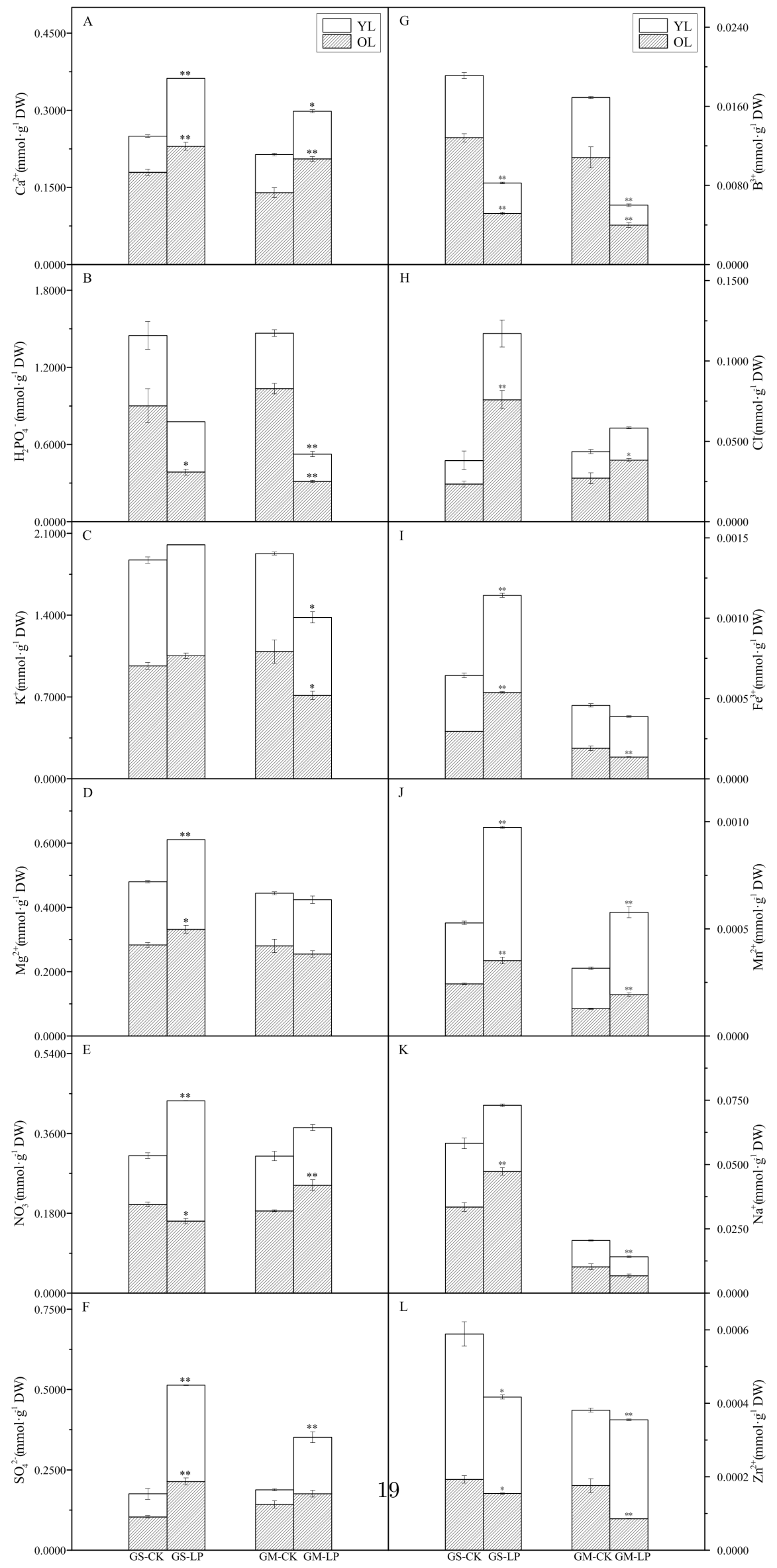



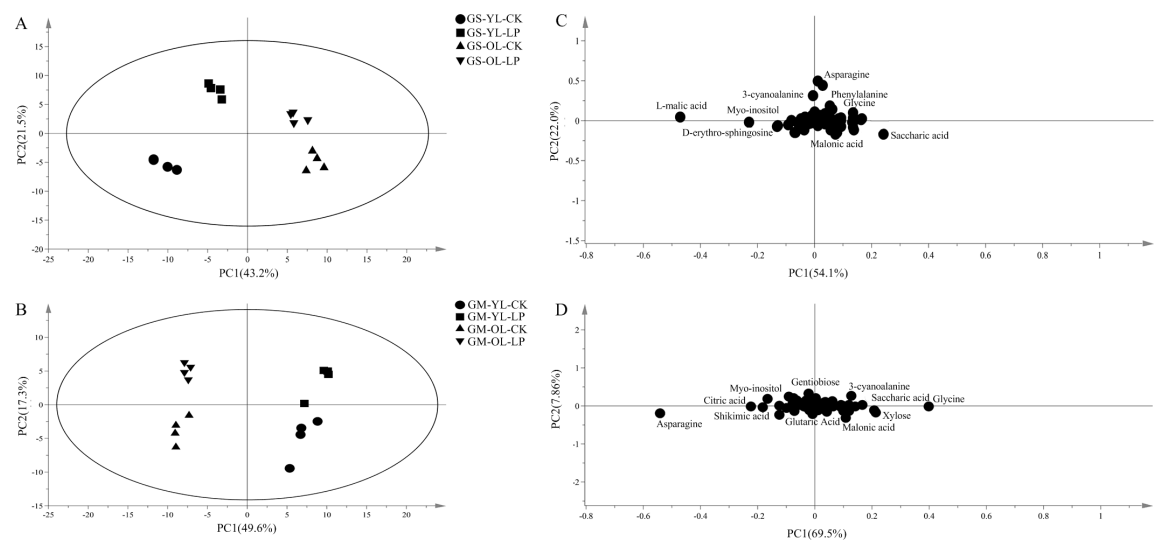


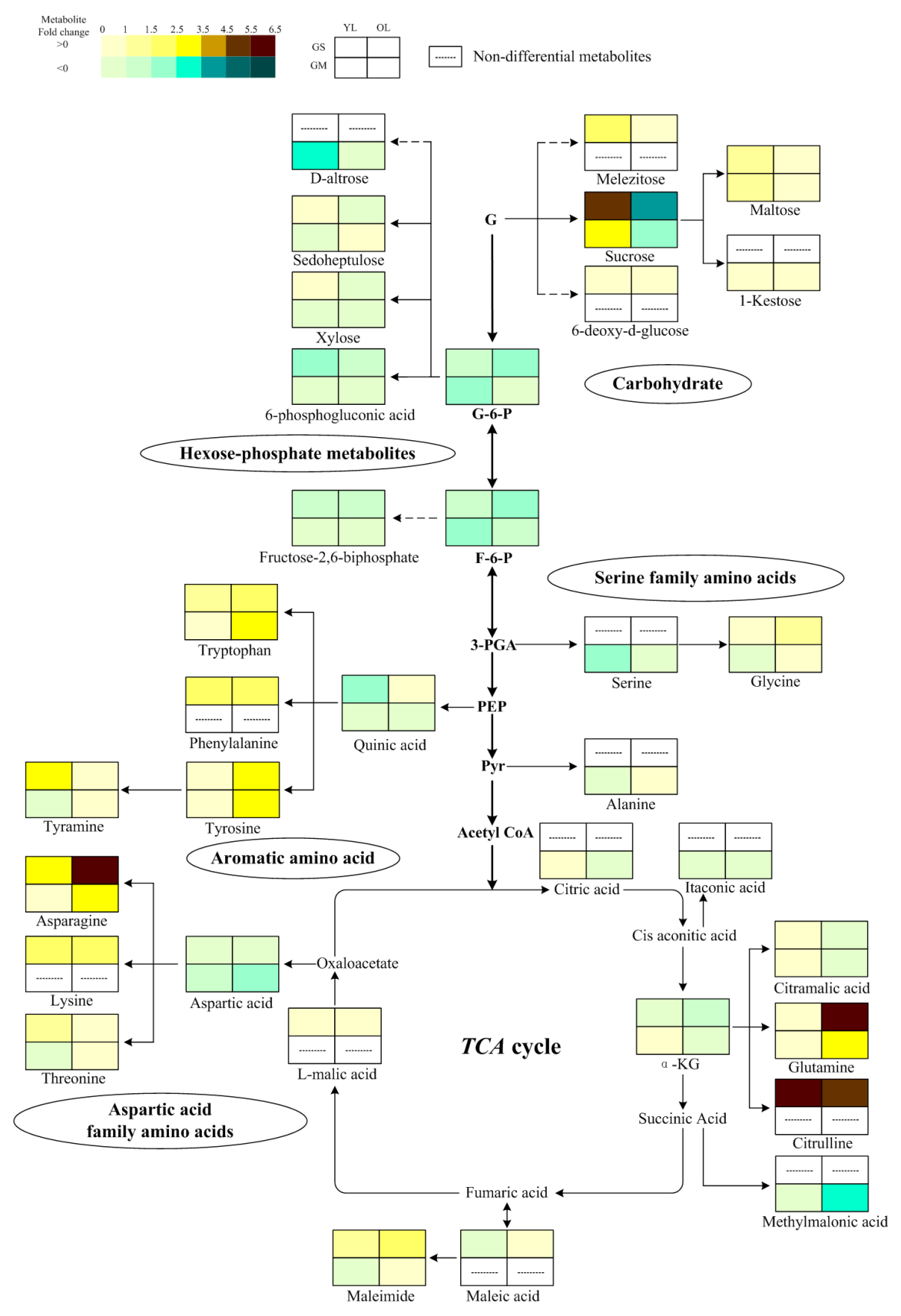

